\title{
TENDON TETHERING IN THE CARPAL TUNNEL DUE TO AMYLOIDOSIS IN BENCE-JONES MYELOMATOSIS
}

\author{
JEFFREY HALLETT
}

\author{
From University College Hospital, London
}

\begin{abstract}
Three cases are reported in which the function of the hand was impaired by tethering of the flexor tendons in the carpal tunnel as a consequence of amyloidosis secondary to myelomatosis. This has not been reported previously and responded well to surgical treatment. The nature of amyloid deposits and their formation in myelomatosis are discussed.
\end{abstract}

Amyloidosis is a condition in which "waxy eosinophilic" deposits are laid down in the tissues (Virchow 1853 , reported by Glenner 1980a). These deposits cannot be removed by physiological processes and may accumulate to cause compression syndromes by replacement of normal tissue. Amyloidosis can occur primarily in the systemic hereditary amyloidoses (Massey 1980) but it is more commonly secondary to other diseases such as chronic infection, rheumatoid arthritis, and myelomatosis. Amyloidosis is seen in about 10 per cent of all cases of myelomatosis although the incidence is much higher in certain types of the disease (Britton 1969; Thompson 1977; DeGruchy 1978; Glenner 1980a).

The three patients reported here were all suffering from myelomatosis of the Bence-Jones or light-chain type which had been complicated by amyloidosis.

\section{CASE REPORTS}

Case 1. A 47-year-old lady, known to have amyloidosis secondary to the Bence-Jones type of myelomatosis, had several prominent subcutaneous amyloid deposits. In June 1976 she lost full extension in the fingers of her right hand. Two months later she noticed wasting of the thenar muscles and loss of sensibility in the distribution of the median nerve. After four months her symptoms had become bilateral and diffuse swellings appeared at the flexor creases of both wrists. Finger flexion was strong but full extension was prevented by tethering of the tendons in the carpal tunnel. Six months later electrical studies showed no sensory or motor conduction in either median nerve. Thirteen months from the onset the left carpal tunnel was explored under general anaesthesia. The median nerve was dissected free and long strands of fibrous material were stripped from the flexor tendons using bone nibblers. Histological examination showed these strands to be amyloid deposits. The passive range of tendon excursion was seen to be improved at operation. This improvement was maintained after operation though some flexion contracture of the interphalangeal joints
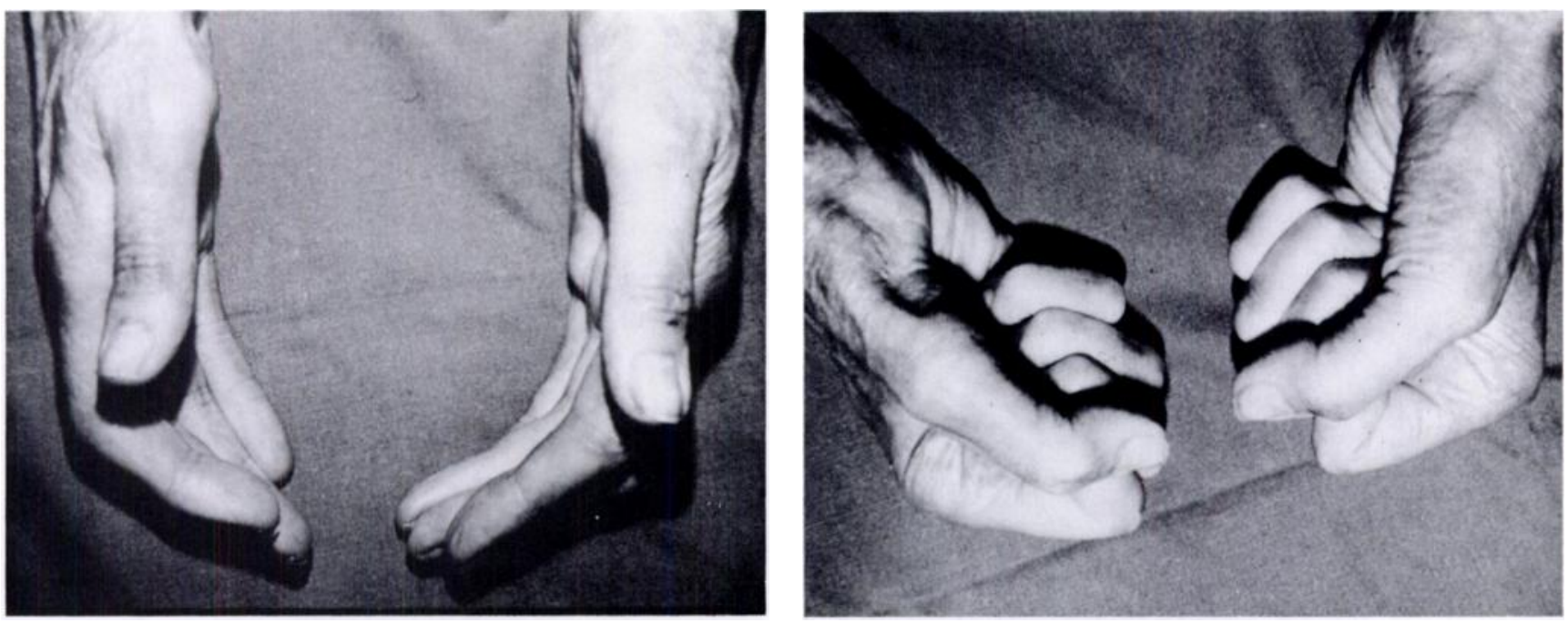

Fig. 1

Fig. 2

Case 1. Both hands three years after operation showing maximal extension and maximal flexion. Note the residual wasting of the thenar muscles.

J. P. Hallett, FRCS, Senior Orthopaedic Registrar

9 Highfield Road, Isleworth, Middlesex TW7 5LD, England

(C) 1982 British Editorial Society of Bone and Joint Surgery 0301-620X/82/3045-0357 \$2.00 


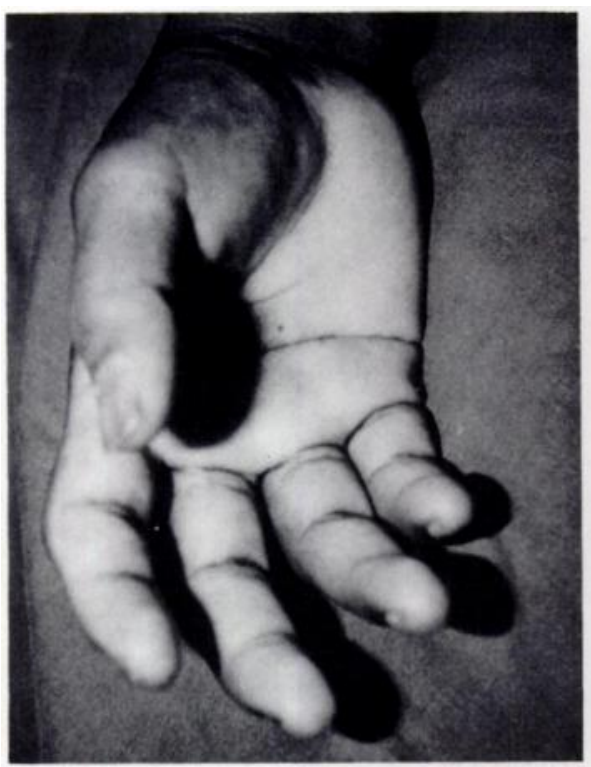

Fig. 3

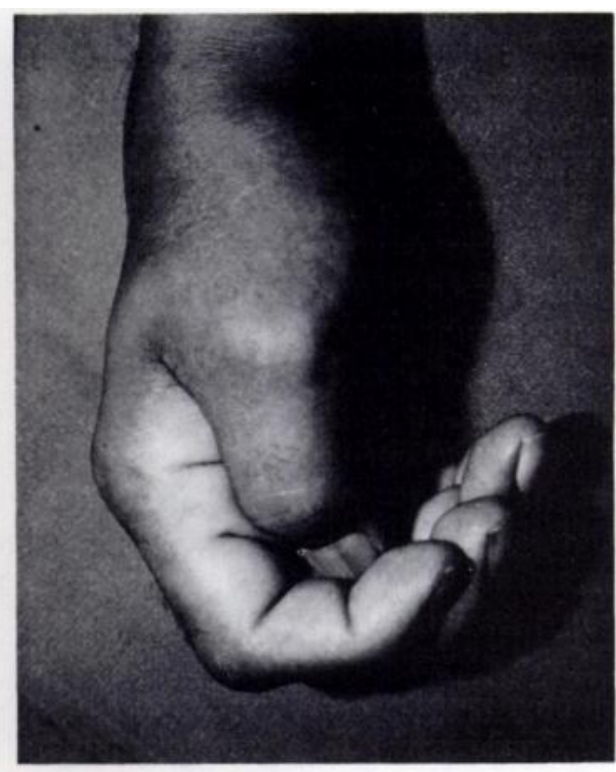

Fig. 4

Case 2. Maximal active flexion before operation and four weeks afterwards. A severe carpal tunnel syndrome had also been relieved.

of the fingers persisted as a result of the prolonged tethering of the tendons at the wrist.

The patient required treatment for anaemia, which postponed operation on the right wrist for three months. By then the patient had traumatic ulceration on the insensitive fingers, and the function of the right hand was reduced to that of a stiff hook. The findings at operation were similar to those in the left wrist.

The patient made a steady recovery and one year after her first operation, was able to write, fasten buttons, hold a glass or cup, and feed herself. There had been appreciable return of sensibility to touch. These improvements were maintained and the photographs in Figures 1 and 2 were taken three years after the first operation.

Case 2. A 45-year-old engineer was diagnosed in November 1978 as having Bence-Jones myelomatosis with a monoclonal excess of kappa light-chain paraproteins in his urine. He had noticed some increasing pain in the right wrist for a few months. Five months after diagnosis of myelomatosis he felt "pins and needles" in the left hand in the median nerve distribution. Medical treatment failed to relieve his symptoms and he was unable to make a tight fist with his left hand. His right hand moved normally but sensibility to pinprick was impaired at the fingertips. At operation five months after the onset of the carpal tunnel syndrome a simple decompression at the left wrist was done under

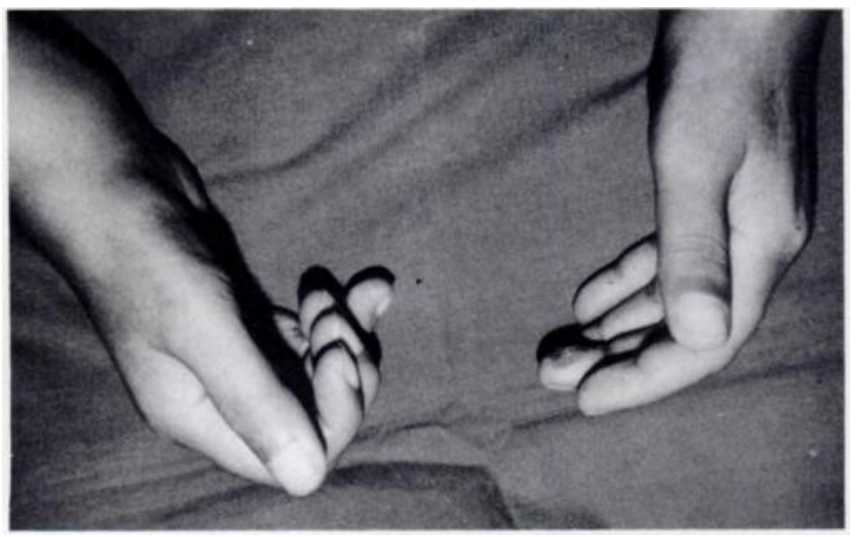

Fig. 5 intravenous regional analgesia. A biopsy of the abnormal paratenon showed it to be amyloid tissue.

At follow-up the left sided symptoms had improved but there were severe symptoms in the right hand. The patient had marked active limitation of finger flexion (Fig. 3), and even on passive flexion the fingertips reached only to four centimetres from the palm. The right wrist was explored under general anaesthesia six months after the left. The transverse carpal ligament was extremely tight because of the mass of tissue in the carpal tunnel. The median nerve and the flexor tendons were surrounded by a tough adherent layer of tissue. This tissue constricted the median nerve and was dissected from it, revealing a length of nerve narrowed to a thickness of four millimetres. The abnormal tissue could be peeled from the tendons in a manner similar to that used to strip the insulating layers off an electric cable or flex. Again it was found that bone nibblers were the most effective tools. Even after this clearance of the carpal tunnel, the tendons did not glide into the forearm on passive flexion of the fingers. This may have been due to more widespread deposits of amyloid. A biopsy taken from an area of bone in the distal radius that was radiologically and macroscopically abnormal reacted mildly when stained with Congo red but could not be positively identified as amyloid. Samples of paratenon showed amyloid deposits in fibrous tissue.

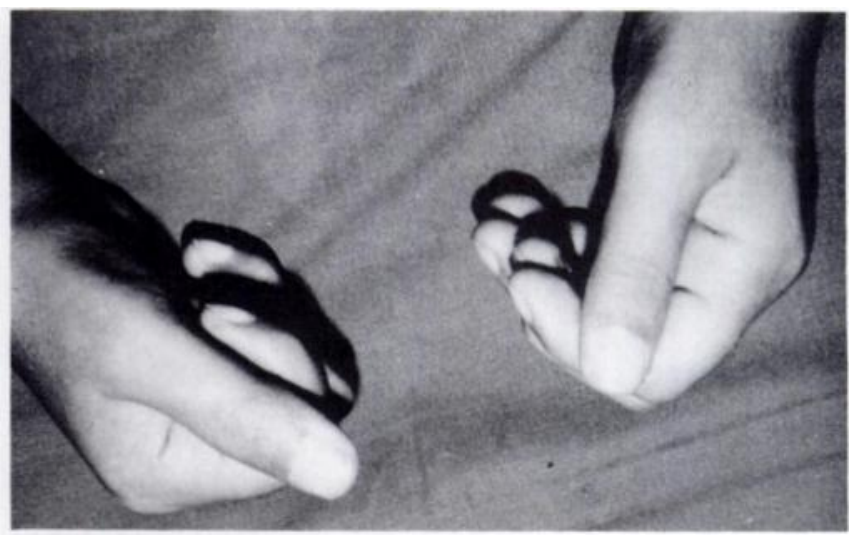

Fig. 6

Case 3. Total range of movement possible before operation. Note the burn on the insensitive left middle finger and the swelling proximal to the right wrist. 
After operation the sensation improved as did the range of flexion of the fingers (Fig. 4). Unfortunately the patient died four months later of chest complications after the internal fixation of a pathological fracture through a myeloma deposit at the hip.

Case 3. This 44-year-old lady noticed pain in the right hand in February 1980). Two days later she woke to find that her index and middle fingers were stuck in flexion. Physiotherapy did not help and swellings appeared at both wrists, while symptoms started in the left hand. After more investigation Bence-Jones myelomatosis was diagnosed, with a monoclonal excess of lambda light-chain paraproteins in the urine. The swellings persisted despite medical treatment for myelomatosis and on arrival in this country the patient was referred for surgical treatment.

When seen in May 1980 the patient had bilateral loss of sensibility in median nerve distribution and swellings just proximal to the wrists In the right hand flexion brought the fingertips to touch the palm, but maximal extension was only four centimetres from the palm. In the left hand extension was full, passive flexion brought the fingertips to the palm, but active flexion was limited to four centimetres from the palm (Figs 5 and 6).

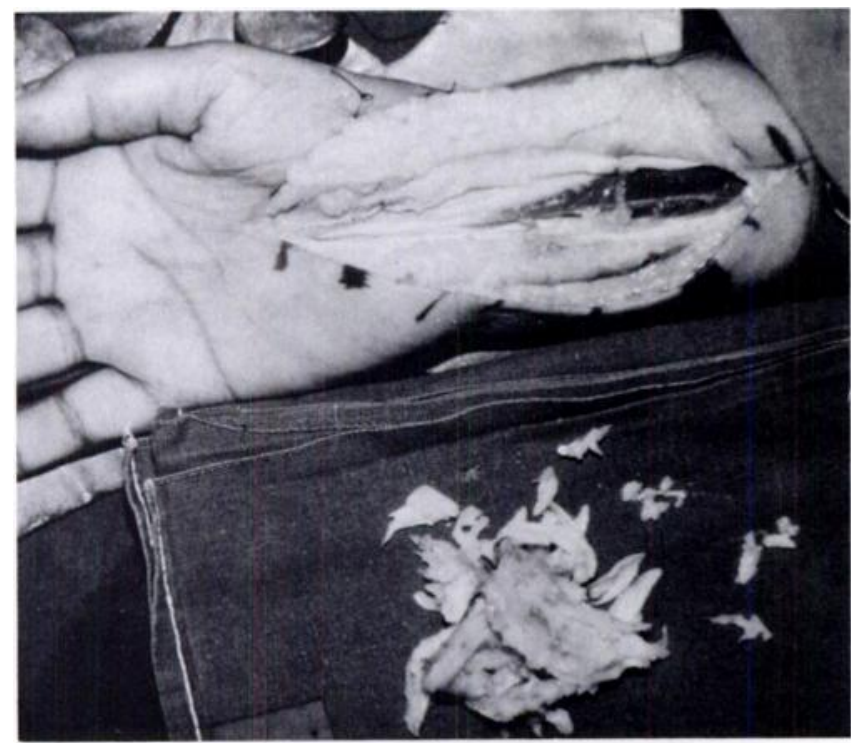

Fig. 7

Findings at operation. Appearance of the carpal tunnel after removal of amyloid material, which is displayed alongside the wrist. The freed median nerve crosses the field just above the flexor digitorum sublimis muscle belly and tendon.

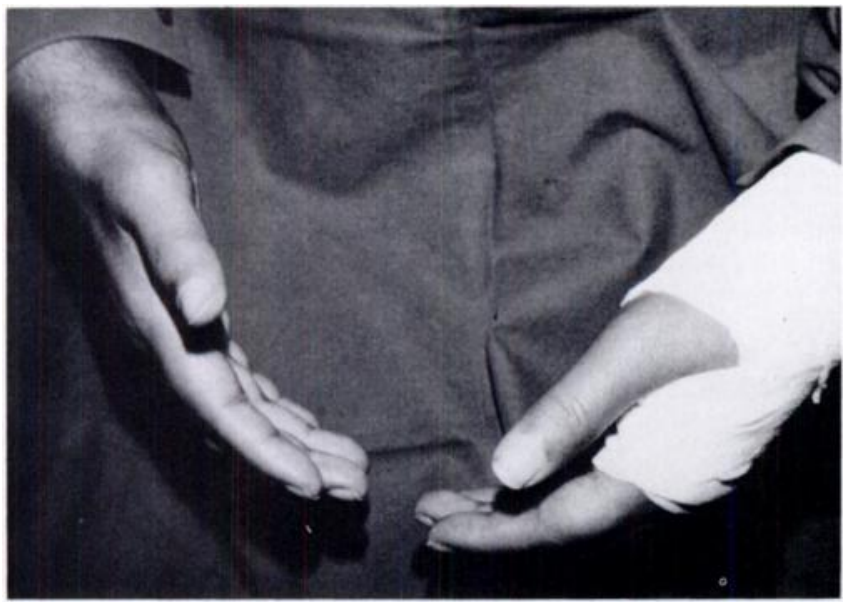

Fig. 8
At operation on the right wrist under general anaesthesia, a large mass of amyloid tissue was cleared from around the median nerve and the flexor tendons (Fig. 7). Bone nibblers were again helpful in some of the dissection. Physiotherapy was started 48 hours after operation and good active flexion and extension were maintained (Figs 8 and 9). A similar exploration and clearance was carried out on the left wrist six weeks later but because of intercurrent ill health active finger movement did not start for two weeks. Unfortunately full active flexion was limited although on passive movement the fingertips touched the palm. Her pain and loss of sensation were still improving when the patient left the country and was lost to follow-up.

\section{DISCUSSION}

Abnormal proteins in myelomatosis. Myelomatosis is characterised by malignant proliferation of plasma cells in bone marrow, liver and spleen, which may cause severe anaemia from destruction of normal marrow, and the typical well-defined osteolytic lesions (Maizels, Prankerd and Richards 1968). The malignant plasma cells usually produce a paraprotein, and in 70 per cent of cases this can be detected as an abnormal band on electrophoresis of plasma proteins. If the paraprotein consists of light chains which have a low molecular weight, it passes out in the urine and does not accumulate in the plasma.

Normal immunoglobulins are composed of both heavy and light chains of polypeptides as shown by x-ray diffraction studies (Solomon 1976). Both types of chains are needed for antibody activity and the light chains are separable into kappa and lambda chains which have slightly different properties. Bence-Jones proteins are the homogeneous light polypeptide chains of immunoglobulins. When heated, their solubility differs from that of normal proteins and this property was used to detect their presence in urine before more accurate methods became available.

Sixty-five per cent of patients with myelomatosis have Bence-Jones proteinuria but many produce other paraproteins as well. Twenty-five per cent of patients

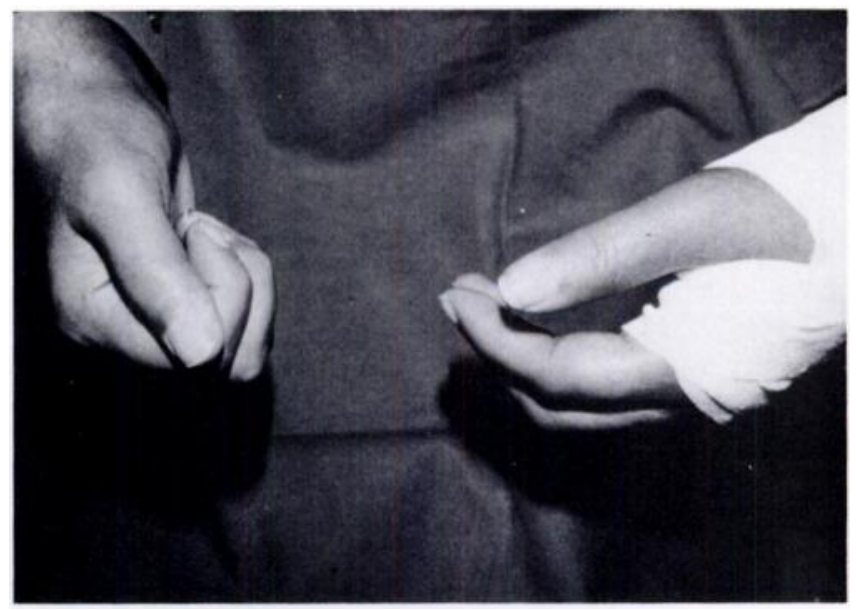

Fig. 9

Case 3. To show maximal extension and flexion 10 weeks after operation on the right wrist and four weeks after operation on the left. Physiotherapy for the left wrist had been delayed by intercurrent illness. 
with myelomatosis produce only Bence-Jones protein, and loss in the urine means that a peak is seldom seen on serum electrophoresis. Special studies of the urine are needed for diagnosis (Stone and Frendel 1975).

Amyloid deposits. Myelomatosis is complicated by amyloidosis in about 10 per cent of cases (Britton 1969; DeGruchy 1978; Glenner 1980a,b). Osserman first considered that immunoglobulins may form part of amyloid material and this has been supported by Glenner's work (Solomon 1976). Amyloid deposits were so named by Virchow because they were "starch-like" on histological staining. Recent work, including electron microscopy, has shown that 90 per cent of amyloid deposits are composed of unique fibrillar elements. X-ray diffraction crystallography of purified fibrils has shown a beta-pleated sheet structure. This sheet structure determines most of the staining and optical properties typical of amyloid (Glenner 1980a).

The fibrillar protein of the amyloid deposits is homogeneous light chain paraprotein (Solomon 1976), and in myelomatosis these deposits are formed from Bence-Jones protein or its components. In vitro 15 to 20 per cent of Bence-Jones proteins are amyloidogenic and precipitate on proteolytic digestion to give fibrils like amyloid (Stone and Frendel 1975).

Amyloid fibrils are resistant to solution in physiological solvents and to normal proteolytic digestion (Glenner 1980a), which means that without treatment there will be an irreversible accumulation of amyloid in the body. This leads to replacement of normal tissue and pressure on vital structures with compression and restriction of movement in enclosed spaces such as the carpal tunnel. The distribution of amyloid material in myelomatosis is the same as that of primary amyloidosis (DeGruchy 1978).

Prognosis in myelomatosis. Untreated patients with myelomatosis have an average survival of 18 months. Cytotoxic therapy with combinations of drugs such as melphalan-prednisone-procarbazine can reduce the production of abnormal protein to less than 25 per cent of that before treatment in over half of the cases. The better the reduction in the production of myeloma protein the better the chance of a good remission rate and survival time. The average survival time for those patients responding to treatment is three years (Maizels et al. 1968; Alexanian et al. 1972; Glenner 1980b). There is no evidence that medical treatment reduces the size of amyloid deposits which are already present. Pure BenceJones myelomatosis has a poorer prognosis than other types when untreated, but its more malignant nature appears to make it responsive to cytotoxic therapy (Stone and Frendel 1975).

Surgical treatment. Many authors refer to the occasional need for operations to decompress the median nerve at the wrist (Maizels et al. 1968; Hardisty and Weatherall 1974; Kyle and Bayrd 1975; DeGruchy 1978). Mechanical tethering of the flexor tendons in the carpal tunnel by amyloid material has not been previously reported. The inability to flex and extend the fingers normally aggravates the loss of function caused by median nerve compression. Simple surgical decompression of the carpal tunnel will relieve the pressure on the nerve but will not free the tethered tendons. Tenolysis is a more difficult procedure than simple decompression of the carpal tunnel, and it has been found that the careful use of small bone nibblers is of great assistance in stripping tenacious amyloid deposits from the tendons. It is essential that there is a programme of early active exercise supervised by physiotherapists.

The three patients reported have been able to resume normal activities such as writing and personal toilet care and all three were anxious to undergo the same operation on the opposite arm. Patients with amyloidosis should be considered for surgical treatment when hand grip deteriorates. The problem may be mechanical tethering of the tendons rather than the diffuse neuropathy (Kyle and Bayrd 1975; Glenner 1980b) which can also occur.

Although the long-term prognosis in myelomatosis is poor, this relatively simple operation provides a worthwhile improvement in the quality of life.

I wish to thank Mr Donal Brooks, Mr A. Ransford, Dr A. Goldstone and Dr R. Souhami for permission to report their cases. I am grateful to Mr Donal Brooks and Dr R. Souhami for advice on the preparation of the text.

\section{REFERENCES}

Alexanian R, Bonnet J, Gehan E et al. Combination chemotherapy for multiple myeloma. Cancer 1972:30:382-9.

Britton CJG. Whitby and Britton's Disorders of the blood. 10th ed. Edinburgh and London: Churchill Livingstone, 1969.

DeGruchy GC. Tumours of lymphoid tissue-the paraproteinaemias. In: Pennington D, Rush B, Castaldi P, eds. Clinical haematology in medical practice. 4th ed. Oxford: Blackwell Scientific Publications, 1978:532-41.

Glenner GG. Amyloid deposits and amyloidosis: the beta-fibrilloses (I). N Engl J Med 1980a: 302: 1283-92.

Glenner GG. Amyloid deposits and amyloidosis: the beta-fibrilloses (II) $N$ Engl J Med 1980b;302:1333-43.

Hardisty RM, Weatherall DJ. Blood and its disorders. Oxford: Blackwell Scientific Publications, 1974;1352-7.

Kyle RA, Bayrd ED. Amyloidosis: review of 236 cases. Medicine 1975;54:271-99.

Maizels M, Prankerd TAJ, Richards JDM. Haematology in diagnosis and treatment. London: Ballière, Tindall \& Cassell, $1968: 204$

Massey EW. Rectal biopsy in carpal tunnel syndrome in amyloidosis. N C Med J 1980; 41(6): 376-7.

Solomon A. Bence-Jones proteins and light chains of immunoglobulins. N Engl J Med 1976;294:91-8.

Stone MJ, Frendel EP. The clinical spectrum of light chain myeloma. Am J Med 1975;58:601-19.

Thompson RB. Disorders of the blood. Edinburgh and London: Churchill Livingstone, 1977:507-31. 